\title{
Research on the Embodiment of Emotional Factors in English Teaching
}

\author{
Wang Yong \\ Feixian Campus, Linyi University \\ Linyi, Shandong, China \\ fxwangyong@126.com
}

\begin{abstract}
With the further development of linguistics, people gradually realize that emotional factors and foreign language teaching are closely related. Foreign language learning efficiency depends not only on the level of students' cognitive ability, but also on the positive or negative factors in the process of English learning. The current foreign language education should get rid of the following two misunderstandings. Firstly, pay attention to the development of knowledge and intelligence but neglect the development of emotion, which result in the "emotional illiteracy". Secondly, ignore the relationship between emotion and cognition, especially the effect of emotion on promoting or blocking language learning. In education, we emphasize on the cultivation of cognitive ability and in the process of developing cognitive ability, we ignore the influence of emotion. The practice has proved that the solution of emotional problems is helpful to improve the students' learning effect and develop the function of positive emotions such as self-esteem, confidence and motivation. However, in the practical English teaching, many teachers pay less attention to the emotional factors, or though they want to pay attention to them, but the training and inspiration go the wrong way and fail to bring the emotional factors' in English learning into role. Teachers should pay attention to the students' will, emotion and needs and attach importance to the establishment of a good relationship between teachers and students, so as to form a suitable learning atmosphere with emotional rapport. Strengthen the positive emotional communication, and make it "catalyst", "stabilizer" and "lubricant" in the process of English teaching.
\end{abstract}

Keywords-English teaching; emotional factors; communication; catalyst; stabilizer; lubricant

In school educational activities, teachers are in the leading position and students are in the dominant position. The two parties' teaching activities involved are people, individuals with rich feelings. So, the teaching process is actually the mutual interaction process of cognition and emotion. Emotional teaching should not only make emotion itself be a goal, but also consciously involve the cultivation of psychological quality and ability, which is related to the will, interest, and interpersonal contact.

Traditional teaching in our country is subject-centered. The defect is that the emotional education excludes from the modern educational activities. Teachers pay more attention to how to make the teaching content be accepted by students. As for the emotional status of students when learning knowledge, they pay no attention. Students become containers in class, which leads to the result that the students lose the initiative and enthusiasm of study. So traditional teaching not only covers students' emotion and humanity but also kills their wisdom and creativity, which results in the low efficiency of traditional education.

There are many definitions about emotional factors. Fehrand Russet (1984:464) have noted in his book Affect in Language Learning: "Everyone knows what an emotion is, until asked to give a definition." Damasio (1994:145) also makes a distinction between the terms emotions (changes in body state in response to a positive or negative situation) and feelings (perceptions of these changes). Besnier(1990:421)refers to further categorization but brings up reservations from the anthropological point of view about cross-cultural validity of distinctions. In the present context, affect will be considered broadly as aspects of emotion, feeling, mood or attitude which condition behavior.

So emotion is that people's attitude and experience when they judge whether the objective things are in line with their own needs. The researchers found that the emotional state of the learners will directly affect their learning behavior and learning effect.

Based on the reflection of teaching reform, the curriculum reform puts forward that teaching should pay attention to the development of every student, their learning methods and learning process, their emotional life and emotional experience. The implementation of emotional teaching is not only the requirements of the teaching rules, but also the requirements of reforming the current teaching situation. As the society is becoming increasingly emphasized English, improving English teaching efficiency and training talents of high-quality and all-round development have become the most obvious characteristics of the time. Emotional teaching came into being along with the tide of the reform of classroom teaching.

The course objectives and contents of modern English subject are clearly defined in the following five parts: language knowledge, language skills, emotional attitude, learning strategies and cultural awareness. To this end, the new curriculum advocates to optimize the relationship between teachers and students and establish a warm, sincere and harmonious emotional atmosphere to provide a driving force for teaching activities.

\section{EMOTIONAL FACTORS IN ENGLISH TEACHING}

Teaching is a bilateral activity between teaching and learning which teachers and students co-participate and center on teaching materials. Teaching materials, teachers and students are the three most basic elements in the teaching process. 


\section{A. Emotional factors in teaching materials}

English curriculum is based on a wide range of contents and forms which are fundamental, ideological and full of time spirits. Most of contents are closer to students' real life, which can stimulate students to explore and experience the emotional factors. Teachers can base on the students' life and learning practice to inspire and guide students to comprehend and experience the dominant or recessive emotion in the teaching material.

\section{B. Emotional factors of teachers}

Teachers are the organizers, participants and managers in the teaching activities, and the teachers' emotion has a great influence on the learners. Psychological believes that when people convey their emotion to accepting object through the change of facial expression, voice and so on, the subject's emotion will have a role in the object and have an influence on object, resulting in a similar feeling with the subject. English teachers will be sure to reveal their own emotion to the English subject and teaching content in the teaching process. Whether it is love, indifference, boredom or disgust will be a subtle influence on the students' emotion to English subject, and further affect students' learning enthusiasm and the development of reason senses. In the teaching activities, the teacher's emotion includes five aspects: (1) the emotion to English subject and the content of teaching material; (2) the emotion to students; (3) the teacher's teaching mood; (4) the expectation of the teaching effect; (5) the expression of emotion.

\section{Emotional factors of students}

Students are not only the main body of learning activities, but also teaching objects. They are immature individuals in the process of physical and mental development, whose emotion is variable and volatile. In teaching practice, the students' emotions are as follows.

1) Emotions to learning activity itself and English subject (such as interest, motivation, anxiety, etc.)

Interest is a kind of cognitive tendency, which is based on the students' learning needs, and this tendency is always accompanied by a good emotional experience. Therefore, it is a strong emotional tendency, which is expressed in likes and dislikes to learning. Interest is also divided into direct interest and indirect interest. The former refers to the interest in things of themselves, such as the students' interest in learning English; the latter is not interested in things themselves, but the needs of the results of the things. Of course, these two kinds of interest can also be transformed into each other, so in teaching process, we should transform the indirect interest into the direct interest, which has a long lasting power function, to meet the needs of the students' psychological development.

Motion is a series of factors that provide motivation and direction for the learners. Learning motivation provides dynamic function(makes students produce learning desire), directional function(makes students' action pointing to a certain target), reinforcing function(determines the degree of learning effort) and maintaining function(helps students to keep their learning perseverance). The motivation in English learning is learners' desire and power to learn English. In English learning, motivation is divided into intrinsic motivation and extrinsic motivation. Extrinsic motivation refers to the external factors influencing on students' English learning, and intrinsic motivation is that foreign language learners show their interest in English learning itself in foreign language learning and get satisfaction and pleasure from learning activities.

Anxiety is an emotional state of anxiety and fear, which is caused by the fear of being unable to reach the goal or overcome the obstacles, leading to the frustration of their self-confidence; or formed by the increased sense of anxiety and guilt. It is always closely related to negative feelings such as anxiety, depression, self-doubt, worry, tension, etc.. Anxiety can be divided into two major categories: facilitating anxiety and debilitating anxiety. The former stimulates students to overcome the difficulties, challenges new learning tasks, and strives to overcome the feeling of anxiety. It is a positive emotion that is positively related to the learners' sense of competition, learning responsibility and learning itself. In the case of moderate anxiety, the learners' learning efficiency will be higher, and the effect will be better, too. But moderation in all things, over-anxiety will waste the energy and spirit used for thinking and memory, so as to affect the smooth progress of the study. Therefore, teachers should be tolerant to students' mistakes, scientifically help students find their own mistakes, protect their confidence, and strive to eliminate the negative effect of anxiety, so that it plays a moderate, reasonable and normal role and is helpful to improve students English learning effectively.

2) Emotions to teachers(i.e. the relationship state between teachers and students)

Since the start of teaching activities of human beings, the relationship between teachers and students has always been one of the core issues of teaching practice. A student's discipline emotion depends on his preferences to the teachers. If a teacher is holding a positive, enthusiastic and trust attitude toward every student in English class and let him feel this kind of attitude in English teaching, and when a student feel genuine care and love, positive expectations and hope from the teacher, he will have the inner emotional experience of being trust, encouragement and motivation, resulting in his trusty and love for the teacher rising from the bottom of his heart. And he will like the discipline because of his likeness to the teacher, accept his teachings, and strive to transform it into action, so as to realize the teacher's expectations. A student who is not satisfied with the teacher's teaching method, or feel the teacher's indifference, or too much criticism, will have a worse learning mood, resulting in his nasty to the teacher, and then the class in his heart. He feels annoyed at the knowledge the teacher teaches and the student's negative emotion will surely influence the smooth acceptance of knowledge and learning.

3) Atmosphere in the classroom (the relationship quality between students and students and the harmony of the teaching situation, etc.)

Any teaching activity is undertaken in the specific environment and the interaction with the environment factors. The use of the emotional factors of the environment can not only provide the conditions for teaching, but also can effectively create psychological atmosphere in according with teaching activities, improve teaching efficiency and develop students' emotional factors. 


\section{COMMUNICATION OF EMOTIONAL FACTORS IN TEACHING}

English teaching is a teaching practice to teach language knowledge, form language skills, develop cognitive strategy and cultivate humanism spirit; it also means interpersonal communication activities in the specific situation. There is not only the information transfer of cognition between teachers and students, but also the emotional information exchange between them. The emotion is a key factor in the teaching activity. Teaching practice is a complex one with the combination of knowledge and emotion. In the three factors of emotion, the teacher's emotion plays a key role of stimulation and adjustment.

\section{A. Emotional communication in the process of cognition}

In the cognitive process, when language knowledge learning and classroom tasks go smoothly and communication with English in created English language environment gets along effectively, teaching effect will be good. Both teachers and students will have a positive emotional experience and produce the feeling of happiness and excitement, otherwise they will be anxiety, unhappiness and disappointed.

In the process of learning and using English, the teachers and students will exchange their emotions contained in the teaching materials. According to their own understanding of teaching materials, teachers explore and give rise to the emotion, or encourage students to initiate other emotions according to their own understanding, and then the teachers and students work together to express this kind of emotion. Teachers and students feel the same edification and infection in the democratic atmosphere of the teaching situation.

In the process of teaching, the manifestation of the teacher's enthusiasm for English learning and teaching content will make him in a state of high spirits, confidence and enthusiasm. This kind of emotional state can affect students' mood, so that they are in a corresponding active state and vice versa. If the teacher's achievement motivation is too strong and produce unsuitable expectations to the students, he will feel anxiety and lack patience in teaching process, which will affect students on producing the corresponding emotional state and in turn seriously influence the teaching process and effect.

\section{B. Emotional communication between teachers and students}

Because teaching activity is a kind of interpersonal activity in a specified situation, both the teachers and the students will consciously or unconsciously communicate interpersonal emotions between them in the process of teachers and students participating in together. Through his own language, action and expression, the teacher can transfer his or her feelings to the students. The emotions of the students are also revealed in their language, action and expression and perceived by the teachers. Their emotions blend together, adjust each other, influence each other and communicate with each other. Comfortable teacherstudent's relationship is established in the emotional interaction and resonance between teachers and students. At the same time, in the cooperation process of using English to complete the task, the emotional exchange between students is very active. The successful completion of the task will produce emotions of infection, counseling, coordination, pleasure and harmony e; while the frustration of completion of the task will generate emotions of tense or disappointment and so on. The content and manner of the emotional communication between students are the main signs of the interpersonal relationship in the class.

The relationship between teachers and students is the equal relationship between people and people based on the individual's psychological needs. In a sense, the relationship between teachers and students in the teaching process is of greater significance than the role relationship between them. A student will believe in teachings only when he gets close to his teacher. "closeness" is a kind of harmonious teacher-student relationship. It is impossible to form a good interpersonal relationship without communication between students and teachers. Then, good interpersonal relationship between teachers and students mainly includes:

\section{1) Establish friend relationship of mutual respect}

The important thing for the relationship between teachers and students is to establish a relationship of mutual trust and mutual respect. Respecting students is respecting their personality and self-esteem. Every student is an individual with self-esteem, personality, thinking and emotion. At the same time, they have a strong sense of trust, dependence and imitation to their teachers. Only when the teacher establish a friend type of interpersonal relationship with his students does he truly respect the students' personality, emotion and choice, and can he went into the inner world of the students. Of course, the students will treat the teacher as a friend, open their minds, and talk and exchange ideas with teachers. The establishment of mutual respect between friends can meet students' psychological needs, and then change his love to the teacher to English learning, which can help to improve students' enthusiasm in English learning and arouse students' interest in learning English.

\section{2) Establish siblings' relationship of mutual caring}

The saying "teacher and student as father and son" means there is a special kind of siblings' relationship between teachers and students. Students tend to treat teachers as parents, or elder brothers or sisters, and teachers also often take students as their own children, or siblings. When a student lacks self-confidence, the teacher should encourage him or her; when a student gives up on himself, the teacher should send warmth; when a student encounter difficulties, the teacher should give help. Only the teacher gives sincere love to his students, can he let the students feel the warmth of love, and then arouse their love to teachers, to the subject the teacher teaches, and improve their interest in the subject.

\section{THE FUNCTION OF EMOTIONAL EXCHANGE}

The humanistic psychology represented by Maslow (A.H.Maslow) ans Rodgers (C.R.Rogers), emphasizes human factors in the learning process, pays attention to learners' willing, emotions and needs, value the establishment of a good relationship between teachers and students, in order to form a harmonious and suitable atmosphere of learning situation. Constructivism psychology advocates that teachers and students, students and students should carry out rich and multi 
communication and call for cooperative learning and interactive teaching in order to create a situation to solve the problem. It is based on the theoretical basis of these psychological theories that they proposed the "emotional attitude" education this curriculum goal. It can be said that in the current English teaching the "situation revolution" takes place, which emphasize on creating teaching situation that get suitable to the students with real language situation, interpersonal warmth, cooperation and interaction. Because of the emotional equivalent function, positive emotional communication is the "catalyst", "stabilizer" and "lubricant" in the process of English teaching.

\section{A. "Catalyst"}

In the English class with the characteristics of interaction, the emotional factors permeate the whole process of teaching and extend outside the process of teaching. Happy and sincere emotion exchange is a great promotion for teachers' teaching and students' learning. Easy, happy, democratic and harmonious teaching atmosphere depends on the good emotional interaction between teachers and students. Happy emotion can stimulate students' motivation to learn English, enhance their interest in English subjects, correct the attitude of English learning, increase the confidence in overcoming difficulties and improve the enthusiasm of participating in the activities of the task.

Only when students participate in the teaching practice with good cooperative emotional state, can they happily accept the input of language knowledge, internalize in their own knowledge system, and then use the language in the real or simulated pragmatic context. Students' happy and full emotion in turn can affect the teacher's words and deeds, encourage teachers to teach with more enthusiasm. Teaching and learning activities lies in the safe and free psychological situation, and students' cerebral cortex is in the excited state, which lead their acceptance, memory, thinking and creativity to achieve the best application state, and promote their mental development. Teachers' motivation and enthusiasm of creative using teaching materials can also effectively be stimulated.

So, in order to make the content of the classroom be novelty, inquiry, interesting and to some degree of operability, teachers should base his lesson preparation on the actual situation of students, depend on the emotion contained in the teaching materials, design manifestation mode in class. For those which have no emotional color content teachers should try to give emotional color to bring life taste into the dull and boring content to arouse the students' emotional resonance. Strong emotional color of the teaching situation can stimulate students' desire and enthusiasm to explore and participate in, improve their thinking level, give rise to their memory and internal efficiency, expand the input of language, promote the development of students' mental and cultivate their sentiment.

\section{B. "Stabilizer"}

In the teaching activities, positive emotional communication can effectively regulate and control the motivation, behavior, attention, emotion and will of teachers and students, so that their language learning can be maintained at the level that both sides expected to realize the target of curriculum..

Modern psychologists believe that a person's success, $80 \%$ depends on the non intellectual factors-emotional factors. American language educator Krashen (1985) also believed that the emotional factors directly affect the second language acquisition. Because English learning is different from other subjects, it must have a sufficient and understandable amount of language input, be understood and accepted by the learners. At the same time, there are also plenty of opportunities for the learners to practice and use English. In this process, the learners' motivation, confidence, anxiety, etc. directly affect the learning effect. Given this, teachers should adjust their teaching mood and emotions, develop their own ability to maintain the dynamic balance of the teaching activities, that is, on basis of a comprehensive understanding of the students' knowledge, skills and emotional factors, teachers should formulate a reasonable teaching plan, choose suitable and varied teaching methods, value students correctly, increasing improve their teaching level and teaching art from their love to students, create safe, democratic and joyful learning environment for students and provide the opportunity of practice and achieving success. In the interaction with the students, teachers naturally show their trust, expectation and respect to students. Accordingly, the students will also reveal emotions of love, trust and expectations to teachers, and actively cooperate with the teachers to self-regulate---regulate and control their learning motivation, methods, attitudes, emotions, attention and so on, and their self-esteem and selfconfidence will be generated, too. When the students' cooperative emotional feedback is perceived by teachers, they will have a better teaching moo; the teaching motivation will be more reasonable; the teaching will be more creative and reflective, which can inspire students' creative and reflective learning, reduce the anxiety in the use of language, effectively strengthen their learning motivation, encourage students to participate in language practice, experience all kinds of emotions in the teaching process and maintain their interest and enthusiasm of English learning.

\section{C. "Lubricant"}

"Lubricant" refers to the quality of the emotional communication between teachers and students can regulate and control cognitive strategies and interpersonal relationship. In the process of cognition, the situation of emotional communication can affect the transmission and processing of cognitive information among the teachers and the students, especially the students' information processing ability and enthusiasm in processing. When emotional exchange is not smooth in teaching process and the teaching is full of pressure and burden, teachers should examine their teaching and psychological state, reflect on their own teaching behavior to meet the reality and needs of students. Teachers also pay close attention to the process of students learning, help students understand their knowledge level and personality characteristics, adjust their expectations to teachers and teaching activities, adjust learning strategies, correctly understand learning content, which will produce positive and happy mood and promote teaching activities smoothly. The harmonious emotional exchange shows that the information transmission is 
smooth, and the information processing is active. The relationship between teachers and students, students and students in the teaching process is the "lubricant" to promote the smooth progress of cognitive process and enhance the teaching effect ". The teachers should control and cultivate their own teaching emotions, run the happy, sincere, and rich emotion through English language learning, study students' emotions, and cultivate their active emotions through teaching materials or people and things that students concern or around them. The philosopher James said: "The most urgent requirements of human nature are: want to be sure." Happy and harmonious emotion exchange is the teacher's sincere, positive evaluation from the bottom of his heart to the students, which is also students' recognition and emotional dependence to the teachers' teaching level and the highest praise between teachers and students. The researchers and theorists have pointed out: "In essence, the classroom is a place where students release and exchange feelings. Good and harmonious interpersonal relationship is the key factor for students to form social competence and emotion." Harmonious and supportive interpersonal relationship is a training field for students to identify, regulate and control and use their emotions and form a healthy personality, which is the most powerful method for performing tasks more smoothly and completing curriculum target in the interactive English teaching. It is the most effective approach to imparting knowledge, educate people and educate oneself, and also an important part of the English curriculum reform.

Attention to the development of students' emotional attitude is one of the important characteristics of the current international education reform. In the new round of education reform in China, for the first time, English Teaching regard the cultivation of students' interest in learning as one of the goals of English curriculum, which requires cultivate the students' learning interest, attitude and self-confidence in English teaching.

\section{CONCLUSION}

Emotional teaching is very important. Only in the primary stage of English learning can teachers cultivate students' interest, confidence, and positive emotional attitude to English learning and enable them to have a lasting, strong interest in learning and learning motivation, which is the key to improve the quality of English teaching. Teachers should consider students as an individual with thought and feelings, update their educational ideas, reexamine the status and role of teachers in English teaching, which is a question that every English teacher must seriously think about. The future learning is not only the development of cognitive ability, but also the acquisition of emotion knowledge and the cultivation of emotion ability.

\section{REFERENCE}

[1] Cheng Xiaotang, Zheng Min. On English Learning Strategies [M]. Foreign Language Teaching and Research Press. 2002

[2] Gao Yihong, Cheng Ying. English Learning Motivation Types and Intensity of Motivation[J]. Foreign Language Research. 2003 (1)

[3] Jia Guanjie. Foreign Language Educational Psychology[M]. Guangxi Education Press. 2003

[4] Wen Qiufang. Developmental patterns in motivation, beliefs and strategies of English learners in China $[\mathrm{J}]$. Foreign Language Teaching and Research. 2002(2)

[5] Xiang Maoying. The influence of effective factors in college English teaching---theories and empirical study[J]. Foreign Language and Their Teaching. 2003(3)

[6] Johnson, K. An Introduction to Foreign Language Learning and Teaching $[\mathrm{M}]$. Foreign Language Teaching and Research Press, 2002.

[7] Zhang Zhengdong. Affective factors in EFL teaching[J]. Journal of Southwest Normal University. 1985(2)

[8] Zhang Zhengdong. English Pedagogy[M]. Shanxi Normal University Press. 2003

[9] David W. Carroll, Psychology of language [M], Beijing: Foreign Language Teaching and Research Press\&Thomson Learning Asia, $2000,331-340$

[10] Harmer, J., The practice of English language teaching[M], Longman Press, 1991, 34-57.

[11] Herbert W. Seliger \& Elana Shohamy, Second language research method[M]. Shanhai Foreign Language Education Press\& Oxford University Press. 1989: 128-1_54.

[12] He. Y., Anxiety in the foreign language classroom[J], In Teaching English in China, 1994, 148-1_52.

[13] Kou Dongquan. Emotional teaching research in China: characteristics, problems and foresight[J]. Journal of Inner Mongolia Normal Universiy(Education Science). 2006(2).

[14] Hu Shan. Exploration on English affective theories[J]. Journal of Shanghai University(Phylosophy and social science. Basic Textbooks). 2004(6).

[15] Jiang Zonghong. Promoting cognition with emotion and emotion to optimize teaching $[\mathrm{J}]$. Primary and Secondary School English Teaching and Research. 2004(5).

[16] Dai Qinghua. Introduction to Emotion Communication in Middle School English Teaching.[J]. Journal of Shandong Normal University of Foreign Language(Basic English Education). 2004(4).

[17] Chen Zhaoxia. Cultivation of students positive emotional attitude in English class.[J]. Basic Education Research. 2004(9).

[18] Zhou Liping. Cultivation of emotional strategies in middle school English[J]. Journal of Ningbo Institute of Education. 2004(1).

[19] Lei Lei, Ouyang Yufei. Emotional education and middle school English teaching $[\mathrm{J}]$. New Curriculum (Teachers). 2005(8). 